\title{
Issues in maintenance and repairs of wheelchairs: A pilot study
}

\author{
Shirley G. Fitzgerald, PhD; ${ }^{1-2^{*}}$ Diane M. Collins, PhD, OTR/L; ${ }^{1-2}$ Rory A. Cooper, PhD; ${ }^{1-4}$ Michelle Tolerico, BS; ${ }^{1-2}$ \\ Annmarie Kelleher, MS, OTR/L, ATP; $;^{1-2}$ Peter Hunt, PhD, MPH; ${ }^{1-2}$ Stephanie Martin, BS; ${ }^{1-2}$ Bradley Impink, BS; $;^{1,3-4}$ \\ Rosemarie Cooper, MPT, ATP ${ }^{1-2}$ \\ ${ }^{1}$ Department of Rehabilitation Science and Technology, School of Health and Rehabilitation Sciences, University of \\ Pittsburgh, Pittsburgh, PA; ${ }^{2}$ Department of Veterans Affairs (VA) Center of Excellence on Wheelchairs and Related \\ Technology, Human Engineering Research Laboratories, VA Pittsburgh Healthcare System, Pittsburgh, PA; Depart- \\ ments of ${ }^{3}$ Physical Medicine and Rehabilitation, School of Medicine, and ${ }^{4}$ Bioengineering, School of Engineering, \\ University of Pittsburgh, Pittsburgh, PA
}

\begin{abstract}
In this pilot study, we assessed wheelchair durability and its effect on user satisfaction. Specifically, we examined the characteristics of the participants' wheelchairs, the types of maintenance and repairs completed, and whether the participants' satisfaction was affected by problems with their wheelchairs. A convenience sample of 130 participants who used wheelchairs as their primary means of mobility was recruited. Participants completed a questionnaire about their wheelchairs, the maintenance and repair history, and their satisfaction levels. Results showed that $26 \%$ of the participants had completed a wheelchair repair in the past 6 months, $16 \%$ had completed general maintenance, and 27\% had completed tire repairs. Neither hours of wheelchair use nor wheelchair age affected repair or maintenance frequency. Participants were generally satisfied with their wheelchairs. Better understanding of wheelchair maintenance and repair issues will guide improvements in wheelchair design and enhance the community participation of individuals who use wheelchairs.
\end{abstract}

Key words: community participation, maintenance, manual wheelchair, outcomes, power wheelchair, satisfaction, wheelchair, wheelchair age, wheelchair repairs, wheelchair use.

\section{INTRODUCTION}

Wheelchair use can enhance the participation of individuals with mobility impairments in community events and social activities [1-2]. However, daily use exposes wheelchairs to assaults from various environmental and user factors. Wheelchair failures often result from exposure to extreme weather conditions and topographic obstacles [3-4]. Furthermore, user weight and movements can exert a great deal of stress on wheelchairs and ultimately lead to wheelchair failures [5-8]. Wheelchair failures, such as broken casters, motor malfunction, and cracks in the frame, not only disrupt the users' daily activities but also can cause

\footnotetext{
Abbreviations: HCPCS = Healthcare Common Procedure Coding System, HERL = Human Engineering Research Laboratories, MS $=$ multiple sclerosis, NPPD = National Prosthetics Patient Database, NVWG $=$ National Veterans Wheelchair Games, $\mathrm{SCI}=$ spinal cord injury, $\mathrm{SD}=$ standard deviation, $\mathrm{VA}=$ Department of Veterans Affairs, VAS = visual analog scale.

This material was based on work supported by the VA Center of Excellence on Wheelchairs and Related Technology, grant F2181C; the Rehabilitation Services Administration, U.S. Department of Education, Long-Term Training Projects: Rehabilitation Technology, grant H129E990004; and the National Institute on Disability and Rehabilitation Research Spinal Cord Injury Model Systems Centers, grant H133N000019.

*Address all correspondence to Shirley G. Fitzgerald, PhD; Human Engineering Research Laboratories, VA Pittsburgh Healthcare System, 7180 Highland Drive, Building 4, 2nd Floor East, 151R-1, Pittsburgh, PA 15213; 412-365-4850; fax: 412-365-4858. Email: sgf9@pitt.edu
}

DOI: $10.1682 / J R R D .2004 .10 .0130$ 
them serious physical harm [9]. However, studies on wheelchair durability are primarily laboratory-based [10-12]. To date, little data exist that characterize and quantify the wheelchair failures experienced by community-dwelling users in everyday real-life settings.

Wheelchairs are a specific class of assistive technology that, when prescribed appropriately based on a personcentered approach, can significantly enhance users' mobility and social participation [13] —an outcome that is supported by numerous studies on wheelchair intervention [14-17]. For example, Trefler et al., who examined the outcomes of wheelchair system intervention with long-term care facility residents, found that individually prescribed wheelchair systems enhanced the users' independent mobility, functional reach, feeling of well-being, and satisfaction [18]. When wheelchair failures occur, not only is the user's ability to perform daily tasks compromised, but serious physical injuries may result. Injuries from wheelchair use have been well documented in studies in Canada and the United States [8-9,19-21]. These studies cited component failure related to wheelchair design as a cause of user injuries. Knowledge of wheelchair reliability may help engineers identify limitations in wheelchair design and prevent injuries.

In addition to causing physical harm, poor wheelchair design can also affect user satisfaction. In a Scottish study, 80 marginal wheelchair users were surveyed on technical, functional, and environmental factors that researchers believed negatively influenced wheelchair propulsion. More than half of the participants reported that their wheelchairs did not sufficiently meet their needs and cited comfort, weight, poor wheel position, and technical problems as reasons [22]. A study of 32 elderly residents in three longterm care facilities found that participants were least satisfied with wheelchair adjustability, comfort, follow-up services, and weight [23]. Another study in the Netherlands examined domestic adaptations and access to assistive technology among 318 individuals with spinal cord injury (SCI); 35.9 percent of the individuals who used manual wheelchairs and 47.5 percent of the individuals who used electric wheelchairs had complaints about their wheelchairs [24].

When assistive technology fails to meet the user's performance expectations, user satisfaction is negatively affected. Lower satisfaction may lead to technology abandonment. In a study of predictors of assistive technology abandonment, Phillips and Zhao found that mobility aids were more frequently abandoned than any other device category, and poor device performance was significantly related to abandonment [25]. In another case series study, Kittel et al. showed that dissatisfaction with wheelchair design and poor wheelchair-related services were major causes of users' premature abandonment of wheelchairs [26]. Although these studies have elucidated the association between poor wheelchair design and user satisfaction, their lack of subjects who are community-dwelling wheelchair users and their use of cross-sectional and case series designs limit the generalizability of their results. Thus, we proposed the current study to examine the association between wheelchair failures and user satisfaction among communitydwelling wheelchair users in everyday real-life settings. More specifically, our objectives in this pilot study were to provide a descriptive analysis of the maintenance and repair issues related to manual (hand-propelled) and power (electric) wheelchairs with the following research questions:

1. What types of repairs and maintenance are performed on wheelchairs? How frequently are repairs and maintenance performed on wheelchairs? Do repairs and maintenance differ with respect to the type of wheelchair used (manual vs power)?

2. Are users of wheelchairs satisfied with their wheelchairs? Do satisfaction levels depend on wheelchair type (manual vs power)?

3. Do repairs and maintenance affect users' levels of satisfaction with their wheelchairs?

\section{METHODS}

We conducted a descriptive pilot study to better understand the wheelchair use, repair, and maintenance issues reported by wheelchair users. Participants completed a questionnaire that collected data about their demographics (e.g., age, diagnosis and/or disability, years with diagnosis and/or disability), satisfaction with their wheelchairs, and the characteristics and repair history of their wheelchairs. Because wheelchairs are affected by how much they are used and in what manner, information was collected on user diagnosis and/or disability and number of hours a day the wheelchair is used. Although these definitions of functional wheelchair use are relatively broad, the original intent of the study was to examine wheelchair use and durability and not the user per se. 


\section{Recruitment}

The University of Pittsburgh and Department of Veterans Affairs (VA) Institutional Review Boards approved this study. A convenience sample was obtained from various sources, including the National Veterans Wheelchair Games (NVWG) and other Human Engineering Research Laboratories (HERL) studies. Individuals over 18 years of age who used a wheelchair as their primary means of mobility were eligible to participate. All recruitment was completed in person. Each study participant signed an informed consent form prior to participation.

\section{Questionnaire}

The questionnaire, initially developed by the research team, was reviewed for content validity by clinicians who prescribe wheelchairs and by individuals who use wheelchairs. Based on the responses of these groups, the questionnaire was modified for improved clarity and relevance. The questions asked in each category are described in Table 1. The full questionnaire is provided in the Appendix (available online only at http:// www.rehab.research.va.gov).

Participants first provided demographic information, including age, sex, ethnicity, and diagnosis and/or disability. Participants then reported characteristics of their wheelchairs, including type, make, model, age, and repair and maintenance history. The make and model were initially asked as open-ended questions then later categorized into common brands. We also used the make and model to classify the wheelchairs according to Healthcare Common Procedure Coding System (HCPCS) codes. Table 2 provides a description of the participants' wheelchairs and the corresponding HCPCS codes. Participants were also asked to report the date that they obtained their wheelchair. Wheelchair age was then calculated by subtraction of the date of the survey from the date the wheelchair was obtained, which resulted in a continuous variable. Additional information was collected regarding where the wheelchair was obtained (e.g., direct sales vendor, rehabilitation clinic), occurrence of repairs at any time during the usable life of the wheelchair, and repairs or maintenance episodes during the past 6 months. Questions regarding repairs included type of repair, who made the repair (i.e., user or vendor), approximate cost of repair, and who paid (i.e., user or vendor).

Participants used a $10 \mathrm{~cm}$ visual analog scale (VAS) to rate their wheelchair satisfaction in 10 categories: satisfaction with use, durability, simplicity of use, comfort,

\footnotetext{
*Available from Centers for Medicare and Medicaid Services (http:// www.cms.hhs.gov).
}

Table 1.

Description of questionnaire. Full questionnaire provided in Appendix (available online only at http://www.rehab.research.va.gov).

\begin{tabular}{|c|c|}
\hline Information Category & How Obtained \\
\hline \multicolumn{2}{|l|}{ Demographics } \\
\hline Age & Birth date. \\
\hline Ethnicity & Categorical: African American, Asian American, Caucasian, Hispanic, other. \\
\hline Diagnosis and/or Disability & Open-ended question. \\
\hline Years with Diagnosis and/or Disability & Date of diagnosis or disability onset. \\
\hline Type & $\begin{array}{l}\text { Categorical: manual, power, scooter. } \\
\text { Make and model. }\end{array}$ \\
\hline Age of Wheelchair & $\begin{array}{l}\text { Year current wheelchair obtained (responses later categorized as described in "Methods" } \\
\text { of main text). }\end{array}$ \\
\hline Place of Purchase & $\begin{array}{l}\text { Categorical: assistive technology clinic, rehabilitation clinic or hospital, direct sales } \\
\text { (wheelchair or medical equipment store). }\end{array}$ \\
\hline Satisfaction with Wheelchair & $\begin{array}{l}10 \mathrm{~cm} \text { visual analog scale (as described in “Methods” of main text) measured satisfac- } \\
\text { tion in } 10 \text { areas: satisfaction with use, durability, simplicity of use, comfort, overall } \\
\text { appearance, dimensions, delivery, transportation, overall fit, and owner's manual. }\end{array}$ \\
\hline
\end{tabular}


Table 2.

Classification of participants' wheelchairs.

\begin{tabular}{|c|c|c|}
\hline $\begin{array}{c}\text { Wheelchair } \\
\text { Type }\end{array}$ & $\begin{array}{c}\text { HCPCS } \\
\text { Code }\end{array}$ & Description \\
\hline Manual & $\begin{array}{l}\text { K0001 } \\
\text { K0002 } \\
\text { K0003 }\end{array}$ & >36 lb, nonadjustable, depot \\
\hline Manual & K0004 & $\begin{array}{l}<34 \mathrm{lb} \text {, adjustable seat \& back } \\
\text { height, some axle adjustment, } \\
\text { high strength, lightweight }\end{array}$ \\
\hline Manual & K0005 & $\begin{array}{l}<30 \mathrm{lb} \text {; adjustable seat height, } \\
\text { back height, axle, \& camber; } \\
\text { ultralightweight }\end{array}$ \\
\hline Power & K0011 & Programmable power wheelchair \\
\hline Power & K0014 & Custom power wheelchair \\
\hline Scooter & E-1230 & Scooter \\
\hline
\end{tabular}

HCPCS = Healthcare Common Procedure Coding System (Centers for Medicare and Medicaid Services).

appearance, dimensions of wheelchair, fit of wheelchair, transportability, delivery of wheelchair, and owner's manual. Participants were not provided definitions of these categories. Participants placed an "X" on the VAS line at the point that best described their opinion. One of the investigators then scored the VAS responses by measuring the distance from the start of the line to the "X." All questions were phrased such that a score closer to 10 indicated more satisfaction. All participants were given an example of how to answer the questions. The survey took approximately 30 minutes to complete.

\section{Variable Definitions}

Table 2 describes the wheelchair classifications involved in this study. Participants were first asked to report whether repairs had ever been completed on their wheelchair and whether maintenance was done regularly. Then, participants were asked to specify the number of repairs and maintenance episodes that had occurred in the past 6 months. If a participant indicated having had a repair(s) or maintenance done, the specifics for each repair (i.e., description, who made the repair, and cost of repair) were asked as open-ended questions. Three experienced rehabilitation engineers reviewed and grouped the descriptions of the repair activities into the following categories: electrical, mechanical, tire-related, frame-related, and accessoryrelated (Table 3). Maintenance activities were documented as such and included items such as oil and lubricant. An additional category was developed for tire replacements.
Table 3.

Wheelchair repair classification.

\begin{tabular}{cl}
\hline Type of Repair & \multicolumn{1}{c}{ Examples } \\
\hline Electrical & $\begin{array}{l}\text { Batteries } \\
\text { Controllers } \\
\text { Joysticks }\end{array}$ \\
Mechanical & $\begin{array}{l}\text { Backrest or headrest problems } \\
\text { Motor problems }\end{array}$ \\
Tire-Related & $\begin{array}{l}\text { Tires } \\
\text { Bearings } \\
\text { Pushrims }\end{array}$ \\
Frame-Related & Frame failures \\
Accessory-Related & Repairs to cushions \\
& Clothing guards \\
\hline \hline
\end{tabular}

\section{Data Analysis}

Data were analyzed with the Statistical Package for the Social Sciences $\left(\right.$ SPSS $\left.^{\circledR}\right)$ software program (SPSS, Inc, Chicago, Illinois). Descriptive statistics (mean \pm standard deviation [SD] for continuous variables and frequencies for categorical variables) were used to initially describe the study sample, wheelchair characteristics, wheelchair repairs, and satisfaction levels. Based on the distribution of the continuous data, appropriate statistics (parametric for normally distributed data and nonparametric for nonnormally distributed data) were used for comparisons. The $\alpha$-level was set a priori at 0.05 . Diagnosis and/or disability was originally asked as an open-ended question then later classified by type (e.g., SCI, MS). To determine whether repairs or maintenance episodes were influenced by diagnosis and/or disability type, we compared diagnosis and/or disability type with wheelchair type, occurrence of wheelchair repairs (yes, no), and occurrence of maintenance episodes (yes, no). Spearman rank correlation $\left(r_{s}\right)$ was used to compare hours in wheelchair with number of repairs and maintenance episodes.

To examine whether repair history differed with respect to type of wheelchair, we used Mann-Whitney tests to compare repair history (represented by number of repairs in the past 6 months) and wheelchair type (manual vs power). Similarly, Mann-Whitney tests were used to determine if satisfaction levels differed by wheelchair type. Subsequent Mann-Whitney tests and Spearman rank correlations examined whether wheelchair satisfaction was related to the occurrence of repairs (yes, no; number in past 6 months). 
Finally, in separate analyses for manual and power wheelchairs, we used Mann-Whitney tests to analyze satisfaction levels and occurrence of repairs (yes,no), and Spearman rank correlations to examine the relationship between number of repairs and maintenance episodes in the past 6 months and satisfaction levels. The number of participants who used scooters was small $(n=4)$, and although these participants are included in the descriptive statistics, they have been eliminated from any stratification that was completed across wheelchair types.

\section{RESULTS}

A convenience sample of 130 individuals was recruited and asked to sign informed consents; 110 returned the questionnaire. Study participants were from 27 different U.S. states $(n=103)$, as well as the United Kingdom $(n=4)$ and Puerto Rico $(n=3)$. Of the participants, $85(77 \%)$ were recruited from the NVWG and 25 were recruited from other sources, such as the Wheelchair Users Registry maintained by HERL. The study participants were predominantly Caucasian ( $n=84,76.4 \%)$, male ( $n=94,85.5 \%)$, veterans ( $n=96,87.3 \%)$, aged $49.2 \pm 10.5$ SD years old, and 19.6 \pm 13.4 SD years postdiagnosis or disability. Years of wheelchair use coincided with number of years postdiagnosis or disability.

Participants reported spending 10.9 \pm 5.0 SD hours a day in their wheelchairs. The diagnoses and/or disabilities reported included cervical spinal cord injury (27\%), thoracic and lumbar SCI (41\%), MS (8\%), cerebral palsy (5\%), amputation (7\%), muscular dystrophy (2\%), spina bifida (2\%), traumatic brain injury (1\%), and postpolio (1\%); the remaining participants (6\%) reported other diagnoses such as Beschi syndrome, spinal meningitis, and transverse myelitis. Although type of wheelchair used significantly differed by diagnosis and/or disability group, the occurrence of or number of repairs or maintenance episodes among the groups did not significantly differ. Similarly, hours of wheelchair use did not affect the number of wheelchair repairs or maintenance episodes.

\section{Research Question 1: Wheelchair Characteristics}

Table 4 lists the characteristics of the participants' wheelchairs. The average wheelchair age was $3.1 \pm 3.1 \mathrm{SD}$ years, ranging from brand new (0.03 years) to 16.5 years. Figure 1 shows the distribution of wheelchair age for the sample. Table 4 shows that 76 participants (69.1\%) used
Table 4.

Characteristics of participants' wheelchairs $(N=110)$.

\begin{tabular}{lc}
\hline \multicolumn{1}{c}{ Characteristic } & Value (n) \\
\hline Wheelchair Age, Mean \pm SD & $3.1 \pm 3.1$ yr $\left(105^{*}\right)$ \\
Wheelchair Type, \% & $69.1\left(76^{\dagger}\right)$ \\
Manual & $1.5(1)$ \\
$\quad$ Depot (K0001, K0002, K0003) & $2.9(2)$ \\
$\quad$ Lightweight (K0004) & $95.6(65)$ \\
$\quad$ Ultralightweight (K0005) & $27.3\left(30^{\ddagger}\right)$ \\
Power & $52.9(9)$ \\
$\quad$ Programmable power (K011) & $47.1(8)$ \\
$\quad$ Customized power (K014) & $3.6(4)$ \\
Scooter (E-1230) & $84.5(93)$ \\
Wheelchair Repairs and Maintenance, \% & $26.3(29)$ \\
Repairs at Any Time & $42.7(47)$ \\
Repairs in Past 6 Mo & $16.4(18)$ \\
Regular Maintenance & $27.2(34)$ \\
Maintenance in Past 6 Mo & $19.1(21)$ \\
Tire Problems in Past 6 Mo & \\
New Tires in Past 6 Mo & \\
\hline *5 questionnaires were missing wheelchair age. \\
${ }^{\dagger}$ questionnaires lacked detailed information on wheelchair type so Healthcare \\
Common Procedure Coding System (HCPCS) code could not be ascertained. \\
${ }_{1}$ 13 questionnaires lacked detailed information on wheelchair type so HCPCS \\
code could not be ascertained. \\
SD = standard deviation.
\end{tabular}

manual wheelchairs, with the majority using ultralightweight (K0005) wheelchairs $\left(n=65,95.6 \%{ }^{*}\right)$. Thirty participants (27.3\%) used power wheelchairs, with only eight $\left(47.1 \%^{\dagger}\right)$ using customized power (K014) wheelchairs. Four participants (3.6\%) used scooters. The majority of participants (68\%) were evaluated for their wheelchairs at a rehabilitation clinic or hospital, 18.7 percent at a wheelchair or medical equipment store (direct sales), 9.3 percent at an assistive technology clinic, and 4.5 percent did not receive any evaluation. Participants received their wheelchairs from an assistive technology clinic (62\%), a rehabilitation clinic or hospital (18\%), and through direct sales (20\%)

Twenty-six percent $(n=29)$ of the participants completed wheelchair repairs in the past 6 months for mechanical, electrical, and frame problems, for an average of $1.7 \pm$ $0.8 \mathrm{SD}$ repairs per person. The 29 participants completed a total of 47 repairs: 5 repairs to the frame, 22 repairs to

\footnotetext{
*Percentage based on 68 participants because of missing data.

${ }^{\dagger}$ Percentage based on 17 participants because of missing data.
} 
mechanical components, and 20 repairs to electrical components. Forty-three percent $(n=47)$ of the sample performed regular maintenance on their wheelchairs. Eighteen participants, fifteen of whom used manual wheelchairs, reported completing maintenance on their wheelchairs in the past 6 months. Maintenance activities included adjustments to wheelchair components (e.g., backrest repositioning), cleaning, and lubrication.

No relationship was found between wheelchair age and the number of repairs completed, the number of maintenance episodes, or the number of tire problems. Wheelchair type (manual vs power) was significantly related to occurrence of repairs $(p<0.001)$; power wheelchairs required more repairs than manual wheelchairs (1.03 $\pm 1.10 \mathrm{SD}$ and $0.22 \pm 0.63 \mathrm{SD}$, respectively).

Thirty-one (28\%) of the participants reported tire problems; eleven reported multiple tire problems. Twentythree (30\%) of the participants who used manual wheelchairs and eight (26.6\%) of the participants who used power wheelchairs reported tire problems. Participants who used scooters did not report any tire problems. In the previous 6 months 21 participants had obtained new tires (17 manual-wheelchair users and 4 power-wheelchair users).

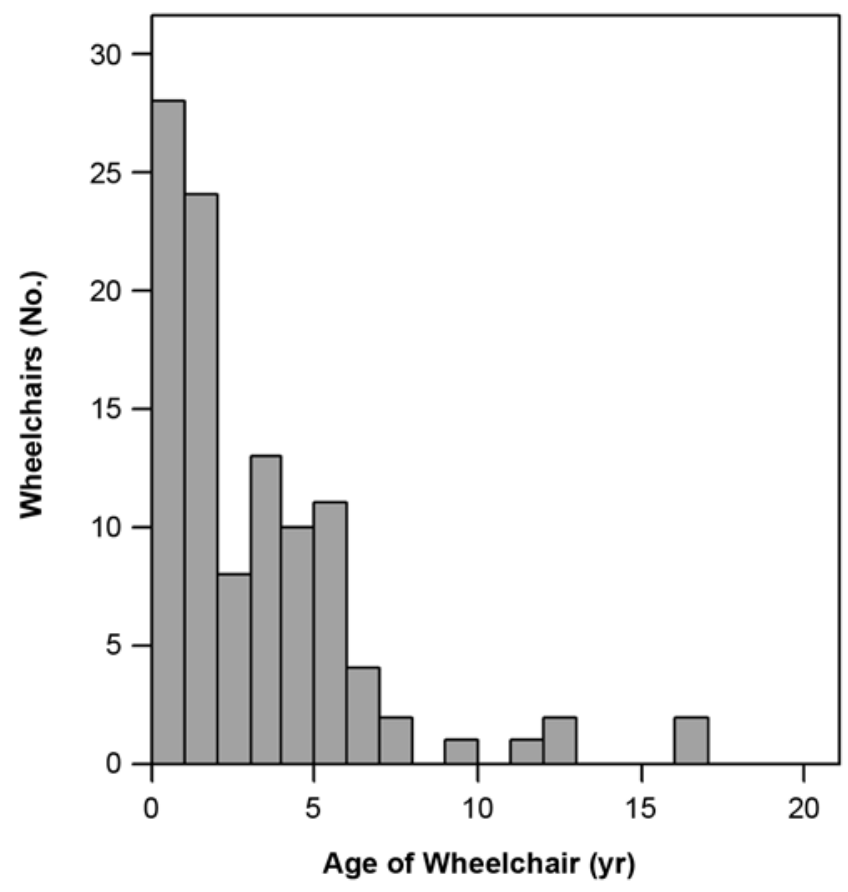

Figure 1.

Age of participants' wheelchairs $(n=105)$.

\section{Research Question 2: Satisfaction Ratings}

Participants were satisfied with their wheelchairs in general and had average VAS scores ranging from 7.0 to 8.2 (10 represents most satisfied). The highest average ratings were found in the categories of wheelchair appearance and simplicity of use; the lowest average ratings were found in the categories of wheelchair comfort and delivery. Figure 2 presents a comparison of satisfaction levels with wheelchair type (manual vs power). Participants who used manual wheelchairs were more satisfied than participants who used power wheelchairs, as demonstrated by the significant differences found in all satisfaction categories $(p<0.05)$, with the exception of appearance, delivery, and owner's manual.

\section{Research Question 3: Impact of Wheelchair Repairs and Maintenance on Satisfaction}

Participants who reported no repairs also reported significantly higher satisfaction with their wheelchairs in all categories compared with participants who reported repairs. These two groups differed significantly in their satisfaction with durability and comfort ( $p<0.05$; Figure 3$)$. Similar findings were obtained when manual and power wheelchairs were analyzed separately.

The number of repairs in the past 6 months was compared with satisfaction. A significant negative correlation was found between number of repairs and satisfaction

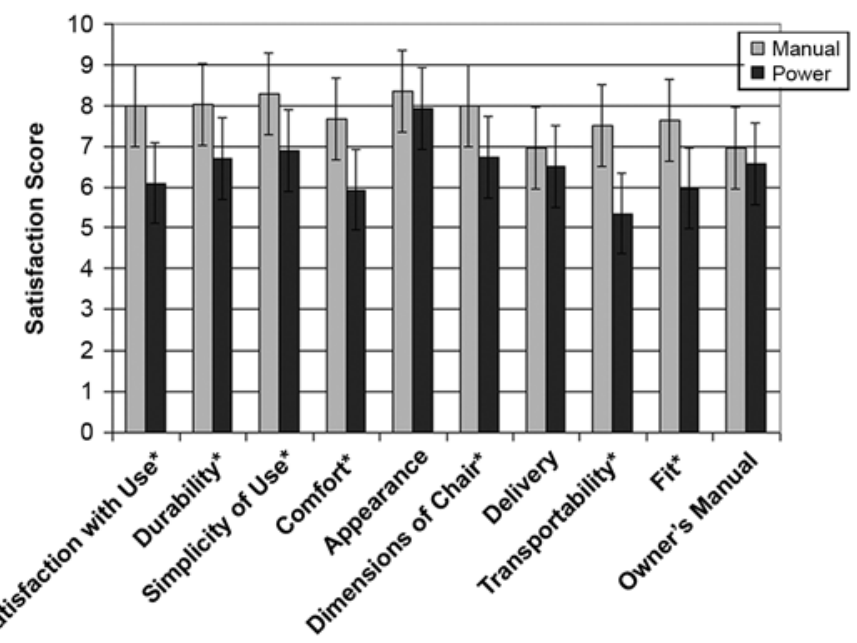

Figure 2.

Satisfaction scores for participants who had $(n=29)$ and had not $(n=81)$ completed wheelchair repairs in past 6 months. Participants rated satisfaction in 10 categories (only 9 included in this analysis) using $10 \mathrm{~cm}$ visual analog scale (10 represents most satisfied). ${ }^{*} p<0.05$. 


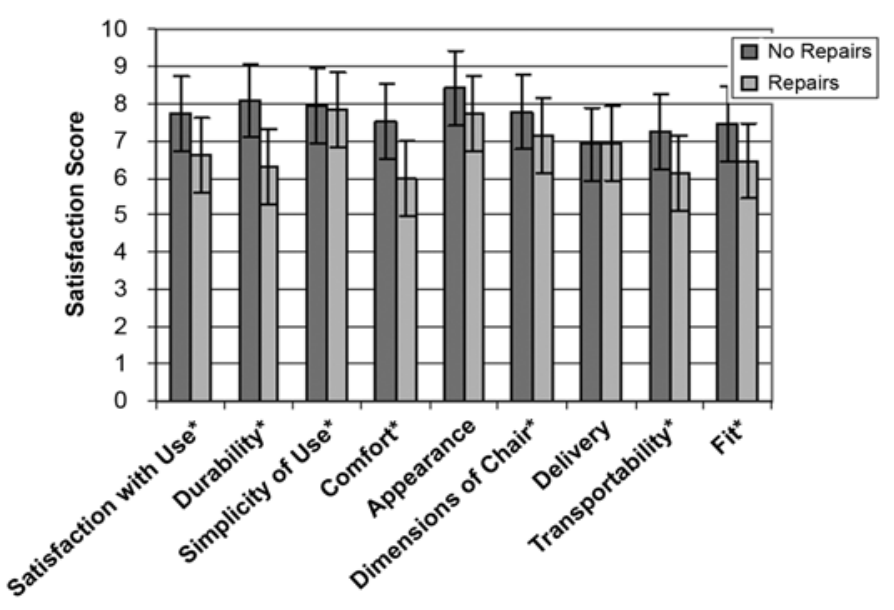

Figure 3.

Satisfaction scores for participants who used manual $(n=76)$ vs power $(n=30)$ wheelchairs. Participants rated satisfaction in 10 categories using $10 \mathrm{~cm}$ visual analog scale (10 represents most satisfied). ${ }^{*} p<0.05$.

with durability $\left(r_{s}=-0.32, p=0.001\right)$, overall satisfaction $\left(r_{s}=-0.21, p=0.03\right)$, satisfaction with comfort $\left(r_{s}=-0.22\right.$, $p=0.02)$, and satisfaction with fit $\left(r_{s}=-0.22, p=0.02\right)$. In addition, significant negative correlations were found between occurrence of maintenance episodes and satisfaction with durability $\left(r_{s}=-0.25, p=0.009\right)$. When we analyzed manual and power wheelchairs separately, the results were slightly different. In participants who used manual wheelchairs, significant correlations were found between number of repairs and satisfaction with comfort $\left(r_{s}=-0.25\right.$, $p=0.03$ ). For number of maintenance episodes, significant relationships were found between number of episodes and overall satisfaction with wheelchair $\left(r_{s}=-0.28, p=0.04\right)$, satisfaction with durability $\left(r_{s}=-0.40, p=0.00\right)$, simplicity of use $\left(r_{s}=-0.26, p=0.03\right)$, appearance $\left(r_{s}=-0.28, p=\right.$ $0.01)$, dimensions $\left(r_{s}=-0.33, p=0.004\right)$, transportability $\left(r_{s}=-0.26, p=0.03\right)$, and fit $\left(r_{s}=-0.24, p=0.04\right)$. No significant differences were found for power wheelchairs regarding number of repairs or maintenance episodes.

\section{DISCUSSION}

\section{Repair Issues}

In this study, a convenience sample of wheelchair users was queried about wheelchair maintenance and repairs. Results indicated that 26 percent of the participants had completed wheelchair repairs in the past 6 months, even though 43 percent performed regular wheelchair maintenance. Although we predicted that older wheelchairs would have required more repairs, this was not supported by the data. Confounding variables, such as the role of functionality, may not have been adequately addressed in the study. Functionality was defined globally as hours of wheelchair use, which at best are participant estimates. However, just because a person is sitting in his or her wheelchair, for example, does not mean that he or she is actively using the wheelchair. Methods exist to track wheelchair use, but because this was a pilot study, we ultimately decided to use hours of wheelchair use and diagnosis and/or disability as broad measures of function, recognizing the limitations imposed. More frequent wheelchair use may affect the durability of the wheelchair and result in more repairs and maintenance than less frequent wheelchair use.

Cooper et al. showed that individuals who used power wheelchairs traveled farther and faster than individuals who used manual wheelchairs [27]. Given that, one would expect power wheelchairs to have more tire problems than manual wheelchairs, but the opposite was true in this study. Manual wheelchairs had a higher occurrence of tire maintenance and replacement than power wheelchairs. Possible explanations include the sampling methodology we used and the type of tire on the wheelchair. Many of the study participants (77\%) were NVWG participants and thus may be more active than individuals who typically use manual wheelchairs but do not participate in the NVWG [27]. The participants' personal maintenance habits may also play a role. Sawatzky et al. determined that a surprising number of individuals using pneumatic tires do not maintain the tire pressure recommended by the manufacturer [28]; some tires were even noted to be below 25 percent of the suggested level. Pneumatic tires offer a better ride but require more maintenance. Power wheelchair tires have thicker walls and treads, which makes them more maintenance-free. Also, many power wheelchairs use flat-free tires.

\section{Satisfaction Issues}

In our study sample, the participants were most satisfied with three characteristics of their wheelchairs: appearance, simplicity of use, and durability. These participants were least satisfied with service delivery and owner's manual. Jedeloo et al. reported as well that their participants were least satisfied with the service delivery process, including the length of time to receive their wheelchairs and the extent to which their opinion was valued in the decision-making process [29]. Post et al. studied satisfaction with service 
delivery among a group of individuals with SCI and also found that satisfaction was low because of problems obtaining equipment and the slowness of the process [24]. Thus, the wheelchair acquisition process and wheelchair delivery are areas needing improvement.

Participants who used manual wheelchairs were significantly more satisfied with most aspects of their wheelchairs than participants who used power wheelchairs. These higher satisfaction ratings could be a factor of the wheelchair design. The vast majority of the manual wheelchairs in our study were ultralightweight (K0005). Manual wheelchairs are mechanically simpler, easier to transport, and ultimately easier to use than power wheelchairs. Although the occurrence or number of repairs did not differ between the two chair types, manual wheelchairs tend to be easier to repair than power wheelchairs. Moreover, manual wheelchair repairs do not necessarily require a specialized vendor since users can make many of the repairs themselves. Power wheelchairs may have more extensive and prolonged repairs, which may affect user satisfaction ratings. Length of time for repairs should be included in future studies.

Our results were similar to those of other studies that examined wheelchairs and daily use. A study in Scotland determined that users experienced difficulties with wheelchair propulsion and daily use [22]. Overall, 59 percent of the participants felt their wheelchairs did not sufficiently meet their needs; technical problems (28\%), general discomfort (31\%), small casters (18\%), and wheelchair weight (16\%) were a few items that participants felt caused inefficient wheelchair propulsion and accomplishment of daily activities. Vachon et al. found that 32 elderly residents of long-term care facilities were most satisfied with the simplicity of use, safety, and effectiveness of their wheelchairs and least satisfied with the adjustability, comfort, weight, and follow-up services of their wheelchairs [23]. In WeissLambrou et al.'s study [30], users of power wheelchairs identified wheelchair comfort as the most important criteria, though comfort was the lowest rated variable in the study. Similarly, satisfaction with wheelchair comfort received a low rating in our study. Other studies have shown comfort to be an important factor to wheelchair users [29]. Studies on individuals in nursing homes indicate that discomfort is a highly prevalent problem [31-32]. Similarly, Bardsley surveyed individuals with a variety of disabilities (e.g., MS, spinal cord lesions) and found that discomfort was a commonly identified wheelchair-seating problem [33].
Our study sample also rated satisfaction with wheelchair transportability low. Power wheelchairs are larger, heavier, and more cumbersome to transport than manual wheelchairs. Users of power wheelchairs typically need specialized vehicles to transport their wheelchairs, which again may affect overall satisfaction. If a user does not have a specialized vehicle to transport his or her wheelchair or if accessible public transportation is not available, community participation may be hampered.

\section{Impact of Satisfaction}

Overall satisfaction with wheelchair durability was high, even though the majority (68\%) of the participants reported wheelchair repairs or maintenance at some point in the past. This satisfaction with durability may be a reflection of the sample, since most participants with manual wheelchairs used ultralightweight wheelchairs. Previous research has shown that ultralightweight wheelchairs have improved durability and longer life expectancy than other manual wheelchairs, such as depots or lightweights [10-11]. Manufacturers now use lightweight, high-strength materials (e.g., titanium) to increase durability [1]. When we controlled for wheelchair age in the analyses, we found a significant relationship between satisfaction with wheelchair durability and number of repairs. Satisfaction with durability decreased over time as number of repairs increased. Continued research on durability and repair history can increase our knowledge of a wheelchair's life beyond laboratory results. Identification of daily obstacles, challenges, and wear-and-tear of power and manual wheelchairs can help manufacturers, designers, and engineers identify areas for improvement. Further, this data would help insurance providers make efficient, informed decisions when purchasing prescribed wheelchairs.

\section{Limitations}

Limitations of the study include convenience sampling and emphasis on veterans who participated in the NVWG. The sample was biased toward users of manual and power wheelchairs; few users of scooters were represented. The participants, especially those with manual wheelchairs, had high-end quality wheelchairs, which could greatly influence the repairs they experienced and their satisfaction. Given that ultralightweight wheelchairs are more durable than other manual wheelchairs, our findings may have been different if other wheelchair 
types had been included. Future work should also include a larger sample from a more diverse population.

Wheelchair durability is probably related to intensity of use, functionality of the user, conditions of use, and age of wheelchair and user. Confounding variables may exist in the relationship between durability and usability, but an analysis of these factors was not possible because of the descriptive nature of the data and the relatively small sample size. Although our analysis showed no relationship between wheelchair age and repairs, the study design was cross-sectional with a 6-month recall of information. Following subjects forward in time may more appropriately assess the occurrence of repairs and usage patterns. In addition, the questionnaire did not cover exposure to different conditions such as rough terrain, which would help describe conditions of wheelchair use.

Recall bias is another limitation of the study. When a repair is completed, the individual may not remember all the details. One way to approach this is to use sources that track wheelchair delivery and repairs. The National Prosthetics Patient Database (NPPD) is a VA-maintained database that tracks all wheelchair prescriptions, deliveries, and repairs for veterans in the VA healthcare system [34]. Future studies could examine the NPPD with respect to repairs completed on groupings of wheelchairs and ultimately link to patient characteristics in other VA-maintained databases (for example, the VA Information Resource Center [VIRec], http:// www.virec.research.med.va.gov/). Additional studies could also obtain a random sample of veterans who receive wheelchairs through the VA.

Although our participants self-reported spending approximately 12 hours a day in their wheelchairs, future work could attempt to better estimate actual wheelchair use. Data on wheelchairs use could be helpful for measurement of satisfaction and community participation because people who travel farther may participate more and be more satisfied. The HERL has developed dataloggers that track distance traveled and velocity on both manual and power wheelchairs [27,35-37]. By collecting actual wheelchair use data, we could better understand the relationship between how far the wheelchair travels and the maintenance and repairs completed on it.

\section{CONCLUSIONS}

This study showed that 26 percent of a convenience sample of wheelchair users required repairs to their wheelchairs in the previous 6 months. The participants who used manual wheelchairs were more likely to maintain their wheelchairs than the participants who used power wheelchairs, which may explain why power wheelchairs required more repairs than manual wheelchairs in the same time period. In general, most participants were satisfied with their wheelchairs, although wheelchair satisfaction was affected by the number of repairs and maintenance episodes. Additional research should follow users and their wheelchairs over time so we may better understand the dynamics of wheelchair repairs and their effect on the user. A better understanding of the types of wheelchair repairs needed will lead to improved wheelchair design and thereby positively affect wheelchair use and community participation.

\section{REFERENCES}

1. Cooper RA. Wheelchair selection and configuration. New York (NY): Demos Medical Publishing; 1998.

2. Karp G. Life on wheels: for the active wheelchair user. Sebastopol (CA): PC Publishing; 1999.

3. Shirado O, Shundo M, Kaneda K, Strax TE. Outdoor winter activities of spinal cord-injured patients. With special reference to outdoor mobility. Am J Phys Med Rehabil. 1995;74(6):408-14.

4. Cooper RA, Wolf E, Fitzgerald SG, Kellerher A, Ammer W, Boninger ML, Cooper R. Evaluation of selected sidewalk pavement surfaces for vibration experienced by users of manual and powered wheelchairs. J Spinal Cord Med. 2004; 27(5):468-75.

5. McLaurin CA, Brubaker CE. Biomechanics and the wheelchair. Prosthet Orthot Int. 1991;15(1):24-37.

6. VanSickle DP, Cooper RA, Boninger ML. Road loads acting on manual wheelchairs. IEEE Trans Rehabil Eng. 2000; 8(3):371-84.

7. VanSickle DP, Cooper RA, Robertson RN, Boninger ML. Determination of wheelchair dynamic load data for use with finite element analysis. IEEE Trans Rehabil Eng. 1996; 4(3):161-70.

8. Kirby RL, Ackroyd-Stolarz SA. Wheelchair safetyAdverse reports to the United States Food and Drug Administration. Am J Phys Med Rehabil. 1995;74(4):308-12.

9. Gaal RP, Rebholtz N, Hotchkiss RD, Pfaelzer PF. Wheelchair rider injuries: causes and consequences for wheelchair design and selection. J Rehabil Res Dev. 1997;34(1): 58-71.

10. Fitzgerald SG, Cooper RA, Boninger ML, Rentschler AJ. Comparison of fatigue life for 3 types of manual wheelchairs. Arch Phys Med Rehabil. 2001;82(10):1484-88. 
11. Cooper RA, Boninger ML, Rentschler AJ. Evaluation of selected ultralight manual wheelchairs using ANSI/RESNA standards. Arch Phys Med Rehabil. 1999;80(4):462-67.

12. Rentschler AJ, Cooper RA, Fitzgerald SG, Boninger ML, Guo S, Ammer WA, Vitek M, Algood D. Evaluation of selected electric-powered wheelchairs using the ANSI/ RESNA standards. Arch Phys Med Rehabil. 2004;85(4): 611-19.

13. Behrman AL. Factors in functional assessment. J Rehabil Res Dev Clin Suppl. 1990;2:17-30.

14. Davies A, De Souza LH, Frank AO. Changes in the quality of life in severely disabled people following provision of powered indoor/outdoor chairs. Disabil Rehabil. 2003;25(6): 286-90.

15. Fuchs RH, Gromak PA. Wheelchair use by residents of nursing homes: effectiveness in meeting positioning and mobility needs. Assist Technol. 2003;15(2):151-63.

16. Nelson A, Powell-Cope G, Gavin-Dreschnack D, Quigley P, Bulat T, Baptiste AS, Applegarth S, Friedman Y. Technology to promote safe mobility in the elderly. Nurs Clin North Am. 2004;39(3):649-71.

17. Brandt A, Iwarsson S, Stahle A. Older people's use of powered wheelchairs for activity and participation. J Rehabil Med. 2004;36(2):70-77.

18. Trefler E, Fitzgerald SG, Hobson DA, Bursick T, Joseph R. Outcomes of wheelchair systems intervention with residents of long-term care facilities. Assist Technol. 2004; 16(1):18-27.

19. Ummat S, Kirby RL. Nonfatal wheelchair-related accidents reported to the National Electronic Injury Surveillance System. Am J Phys Med Rehabil. 1994;73(3):163-67.

20. Kirby RL, Ackroyd-Stolarz SA, Brown MG, Kirkland SA, MacLeod DA. Wheelchair-related accidents caused by tips and falls among noninstitutionalized users of manually propelled wheelchairs in Nova Scotia. Am J Phys Med Rehabil. 1994;73(5):319-30.

21. Calder CJ, Kirby RL. Fatal wheelchair-related accidents in the United States. Am J Phys Med Rehabil. 1990;69(4): 184-90.

22. Perks BA, Mackintosh R, Stewart CP, Bardsley GI. A survey of marginal wheelchair users. J Rehabil Res Dev. 1994; 31(4):297-302.

23. Vachon B, Weiss-Lambrou R, Lacoste M, Dansereau J. Elderly nursing home residents' satisfaction with manual and powered wheelchairs. In: Proceedings of the Annual RESNA Conference; 1999 Jun 25-29; Long Beach, CA. Washington (DC): RESNA Press; 1999. p. 221-23.
24. Post MW, van Asbeck FW, van Dijk AJ, Schrijvers AJ. Services for spinal cord injured: availability and satisfaction. Spinal Cord. 1997;35(2):109-15.

25. Phillips B, Zhao H. Predictors of assistive technology abandonment. Assist Technol. 1993;5(1):36-45.

26. Kittel A, Di Marco A, Stewart H. Factors influencing the decision to abandon manual wheelchairs for three individuals with a spinal cord injury. Disabil Rehabil. 2002;24(1-3): 106-14.

27. Cooper RA, Thorman T, Cooper R, Dvorznak MJ, Fitzgerald SG, Ammer W, Song-Feng G, Boninger ML. Driving characteristics of electric-powered wheelchair users: how far, how fast, and often do people drive? Arch Phys Med Rehabil. 2002;83(2):250-55.

28. Sawatzky BJ, Denison I, Kim WO. Rolling, rolling, rolling. Rehab Manag. 2002;15(6):36-39.

29. Jedeloo S, De Witte LP, Linssen BA, Schrijvers AJ. Client satisfaction with service delivery of assistive technology for outdoor mobility. Disabil Rehabil. 2002;24(10):550-57.

30. Weiss-Lambrou R, Tremblay C, LeBlanc R, Lacoste M, Dansereau J. Wheelchair seating aids: how satisfied are consumers? Assist Technol. 1999;11(1):43-53.

31. Shaw CG. Seat cushion comparison for nursing home wheelchair users. Assist Technol. 1993;5(2):92-105.

32. Shaw G. Wheelchair seat comfort for the institutionalized elderly. Assist Technol. 1991;3(1):11-23.

33. Bardsley GI. The Dundee seating programme. Physiotherapy. 1984;70(2):59-63.

34. Kauzlarich JJ, Thacker JG. Wheelchair tire rolling resistance and fatigue. J Rehabil Res Dev. 1985;22(3):25-41.

35. Hoover AE, Cooper RA, Ding D, Dvorznak MJ, Cooper R, Fitzgerald SG, Boninger ML. Comparing driving habits of wheelchair users: manual vs. power. In: Proceedings of the Annual RESNA Conference; 2003 Jun 19-23; Atlanta, GA. Washington (DC): RESNA Press; 2003.

36. Arva J, Fitzgerald SG, Cooper RA, Spaeth DM, Boninger ML. Long-term monitoring of wheelchair usage with and without the Yamaha JWII power-assisted wheelchair hubs. In: Proceedings of the Annual RESNA Conference; 2001 Jun 22-26; Reno, NV. Washington (DC): RESNA Press; 2001. p. 361-63.

37. Spaeth DM, Arva J, Cooper RA. Application of a commercial datalogger for rehabilitation research. In: Proceedings of the Annual RESNA Conference; 2000 Jun 28-Jul 2; Orlando, FL. Washington (DC): RESNA Press; 2000. p. 313-15.

Submitted for publication October 6, 2004. Accepted in revised form August 31, 2005. 